\title{
On The Pricing of Credit Spread Options: a Two Factor HW-BK Algorithm
}

Joao B. C. Garcia, Ph.D. (contact person)

Senior Quantitative Analyst

Risk Methodology

Dexia Holding

Square de Meeus 1

B-1012 Brussels

Tel. +322213.5823

Fax. +322218.5880

Email: crisj@dexia.com(work)

Helmut Van Ginderen

Risk Methodology

Dexia Bank

Galileilaan 5

B-1012 Brussels

Tel. + 322204.3535

Fax. + 322204.49 .41

Email: helmut.van.ginderen@artesiabc.be

Reinaldo C. Garcia, Ph.D.

Department Energy, Transportation and Environment

DIW - Deutsches Institut fur Wirtschaftsforschung

Königin Luise-Straße 5

D 14195 Berlin

Germany

Tel. + 493089789666

Fax. 49 (0)30 89789113

Email:rgarcia@diw.de 


\title{
On The Pricing of Credit Spread Options: a Two Factor HW-BK Algorithm
}

\author{
João Garcia ${ }^{1}$, Helmut Van Ginderen and Reinaldo Garcia
}

\begin{abstract}
Summary
In this article we describe what a credit spread option (CSO) is and show a tree algorithm to price it. The tree algorithm we have opted for is a two factor model composed by a Hull and White (HW) one factor for the interest rate process and a Black-Karazinsky (BK) one factor for the default intensity. As opposed to the tree model of Schonbucher 1999 the intensity process cannot become negative. Having as input the risk free yield curve and market implied default probability curve the model by construction will price correctly the associated defaultable bond. We then use Market data to calibrate the model to price an at the money (ATM) CSO call and then test it to price an out of the money (OTM) Bermudan CSO call on a CDS. Furthermore the discussions in this paper show in practice the difficulties and challenges faced by financial institutions in marking to market those instruments.
\end{abstract}

\section{1) Introduction}

\footnotetext{
${ }^{1}$ João Garcia is a Senior Quantitative Analyst at the Credit Modeling Group at Dexia Group in Brussels, Helmut Van Ginderen was head of the Risk Modeling Group at Dexia Bank in the time of the publication (and is currently a Senior Analyst at the Credit Research ABS in Fortis Bank in Brussels), and Reinaldo Garcia works at the Dept. of Energy, Transportation and Environment at DIW (German Institute for Economic Research in Berlin. Any comment for this paper should be sent to João Garcia at crisj@dexia.com.
} 
In recent years the market for credit derivatives has experienced an extremely huge growth. These instruments are being actively used not only for hedging purposes but also as a way to improve return on capital.

A bank might use credit derivatives to manage its portfolio of credit risk. Moreover with a credit derivative a bank can sell credit exposure and still keep a good relationship with an important client. For a bank credit (derivative) instruments have become the most efficient way to transfer credit risk. Moreover its use to optimize the allocation of regulatory capital might be seen as a way to arbitrage the regulators.

There are two main approaches to modelling credit derivatives. In the first approach a credit derivative is modelled as a contingent claim on the assets of the firm. These are the so called firm value models and were initiated by Black and Scholes [1973] and Merton [1974], followed by Longstaff and Schwartz [1995] and Das [1995] among others. For a comparison among the different models we refer to Eom et alli [2000].

The idea behind firm value models is that default occurs when the firm value process reaches a certain boundary (e.g. book value). These models are generally thought to give a good estimate of the pay-off (loss) distribution function of a portfolio of credits. It is one of the reasons why the Merton model has been rather successfully used in the CreditMetrics and KMV commercial packages for credit risk. Moreover the assumptions of the Merton model underlie the use of the multi-normal distribution function currently in use on the gaussian copula approach of basket pricing methodologies (see e.g. Garcia et alli [2002]). One of the problems faced by firm value models is that the firm value is not a direct observable process. This makes that default probabilities generated by the model will not necessarily match the ones implied from the CDS market.

In the second approach, known as intensity based models, the time of default follows a point process with deterministic or stochastic intensity where the jump (to default) time is totally 
unpredictable. This approach has been followed by Duffie and Singleton[1994], Jarrow and Turnbull[1995], Jarrow, Lando and Turnbull[1997], Schonbucher [1998] and Lando[1998], among others.

Another way of distinguishing between the two approaches might be seen in the sort of numerical techniques used. In firm value models we find problems similar to the ones used when extendind the BS formula to include American options, dividends, stochastic interest rates and so on. While intensity models are more akin to the term structure modelling problems ${ }^{1}$.

One of the most actively traded credit derivatives is a credit default swap (CDS). A CDS provides insurance in the event of default (called a credit event) of a particular company (called the reference entity). In this work we show an approximation to the pricing of a CSO option on an a CDS.

In this paper we built on the work of Schonbucher [1999] which belongs to the class of intensity models. The additional features of this work are: i) we use the HW model for the interest rate and the BK model for the hazard rate process, while Schonbucher uses the HW model for both processes; ii) we show in practice the difficulties involved in the calibration of the algorithm; iii) after the calibration is done (using market data) we use the model to price a Bermudan CSO on a CDS and compare the price given by the model with the price given by a market maker; iv) we give a practical view of the problems financial institutions currently face when keeping track of marking to market of CSO's.

Although the model may certainly accommodate a correlation function between the dynamics of interest rates and hazard rates we will consider that both processes are not correlated. The main reason for it is that the $\mathrm{CSO}$ market is not yet mature. I.e. there is not data enough available to make the calibration to correlation reliable enough to be worthwhile the job. The calibration for correlation is a rather time consuming step and one needs data to make it reliable. Moreover as it 
is mentioned in Schonbucher [1999] the impact of uncertainties in recovery rates is much higher than assumptions on correlation.

The paper is organized as follows. In section 2 we will describe the model used for the credit process. In section 3 we describe a credit spread option (CSO) and how this instrument is related to the risk free and intensity rates processes. The integration of interest and hazard rates in a two factor Hull and White (HW) Black Karazinsky (BK) is briefly described in section 4. Section 5 contains numerical results for an approximation of Bermudan CSO on a CDS and section 6 has the comments on the results.

\section{2) The Credit Event Process}

There are several very good references in the literature for a description of the default process as for example Schonbucher [1999-2], Lando [1998], Duffie and Singleton [1995] and Jarrow et alli [1997]. For conciseness we have kept the description of the default process to the bare minimum necessary to follow the article.

Instead of modelling the firm value we will model directly the time of default. We will assume that the default event follows a Poisson process with stochastic intensities (hazard rates).

In the literature this is called a Cox process (see Bremaud [1998] or Lando [1998] for more details).

Consider that $\mathrm{Q}(\mathrm{t}, \mathrm{T})$ is the cumulative default probability viewed at time $\mathrm{t}$ for the period $[\mathrm{t}$, $\mathrm{T}]$. In a Cox process $\mathrm{Q}(\mathrm{t}, \mathrm{T})$ is given by:

$$
Q(t, T) \equiv 1-\exp \left(-\int_{t}^{T} \lambda_{t}(u) \cdot d u\right)
$$


where $\lambda_{t}(u)$ is the instantaneous forward rate of default at time $u$ viewed at time $t$ (the intensity of the Cox process). If one has $\mathrm{Q}(\mathrm{t}, \mathrm{T})$ then $\lambda(\mathrm{t}, \mathrm{T})$ will be given by:

$$
\lambda(t, T) \equiv-\frac{\partial}{\partial T}(\ln Q(t, T))
$$

In the following section we show how the hazard rate and the cumulative default probability are used to price a credit spread option.

\section{3) Credit Spread Options}

Credit spread options (CSO) are designed to give cheap protection in case of spread changes.

As the bond market is less liquid than the CDS market, instead of buying a put option on a bond one might want to buy a call option on a CDS.

Alternatively an investor might decide to sell a CDS instead of investing in a bond. The reason for it is that currently CDS's give higher returns without the cost of funding which exists in the case of a bond investment. One of the possible hedges for the CDS position would be a CSO call option on a CDS.

One should keep in mind that for the moment CSO's are still rather exotic instruments traded over the counter only. Moreover the contracts are very rich in detail and we will be presenting one sort of structure only.

In the next section we describe the algorithm for pricing an option on a defaultable bond, and then the algorithm is adapted to price an option on a CDS. 


\section{1) Credit Spread Put Options on a Bond}

Consider $\mathrm{B}_{\mathrm{D}}(\mathrm{t}, \mathrm{T})$ the price at time $\mathrm{t}$ of a defaultable bond with maturity $\mathrm{T}$. Assume that at time $t$ the bond is being traded at a yield spread of $y_{t}$ above the yield on a risk free identical bond $\left(B_{R F}(t, T)\right)$. A credit spread put option with expiry date $T_{\exp }\left(T_{\exp }<T\right)$ gives the holder the right to sell the bond for a pre-specified yield spread $\mathrm{K}$ (the strike of the option) in case the yield spread $\mathrm{y}_{\mathrm{t}}$ goes higher than $\mathrm{K}$.

As is normal market practice in what follows we will be considering that at the time of default the bond will be worth a recovery factor (1-L) multiplied by the notional, where $\mathrm{L}$ is the loss factor. Any expected accrued interest is supposed to have been counted for in the recovery factor ${ }^{2}$. For a description of alternative models of recovery we refer to Schonbucher [1999-2].

Consider that $\mathrm{r}(\mathrm{s})$ is the continuous short term interest rate at time $\mathrm{s}$, and as before $\lambda(\mathrm{s})$ is the hazard rate for the given entity at time s seen at the time of pricing (for simplicity the second index has been omitted). The price of the defaultable bond is given by ${ }^{3}$

$$
\left.B_{D}(t, T)=E_{t}\left[e^{-\left(\int_{t}^{T}(r(u)+L \cdot \lambda(u) d u)\right.}\right)\right]
$$

If one assumes independence between the intensity process and the risk free rate process we have:

$$
\left.B_{D}(t, T)=B_{R F}(t, T) \cdot E_{t}\left[e^{-\left(\int_{t}^{T}(L \cdot \lambda(u) d u)\right.}\right)\right]
$$


For the payoff of a CSO suppose $\mathrm{K}$ is the strike spread and $\mathrm{T}_{\text {exp }}$ the expiry date. The payoff of the credit spread (put) option at the expiry date is given by:

$$
C S O_{\text {payoff }}\left(T_{\exp }\right)=\left[e^{\left(-K \cdot\left(T-T_{\exp }\right)\right)} \cdot B_{R F}\left(T_{\exp }, T\right)-B_{D}\left(T_{\exp }, T\right)\right]^{+}
$$

where the index $(x-y)+$ means the maximum between $x-y$ and zero. The price of the option at time $\mathrm{t}$ is given by:

$$
C S O(t)=E_{t}\left\lfloor C S O_{\text {payoff }}\left(T_{\exp }\right)\right\rfloor
$$

where as before $E_{t}$ is the expectation at time $t$ under the equivalent martingale measure.

\section{2) Credit Spread Option on a CDS}

A call option on a CDS gives the holder the right to buy a CDS with a certain strike rate $\mathrm{K}$ at (or until, depending on the nature of the option) a certain date $\mathrm{T}_{\exp }$. With this instrument the buyer acquires the right of buying protection on the default of a general bond (which is detailed in the CDS contract).

In this study we will assume that one can build a CDS synthetically by taking positions in a defaultable and a risk free floating rate note (FRN). An option on a CDS could then be approximated by using the algorithm of the last section taking into account for FRN's instead of bonds. The results of the approximation are discussed in section 5 .

A long position on a CDS can be synthetically built by a short position in a defaultable FRN and a long position in a risk free FRN. In order to see it consider the cash flows of each side of 
the position: in case there is no default the short side will pay the risk free forward rate plus the (CDS) spread, while from the long side one will receive risk free forward, generating a net

position of the CDS spread. In case there is default the short side will deliver the recovered value of the defaulted FRN while receiving (in full) the notional, the net value for the short side is the loss in case of default (we refer to Schonbucher [1999-2] for more details).

In this way a call on a CDS rate is identical to a put on a defaultable FRN note, and we use the eq. 5 above just that in place of a bond we have a FRN. In this case the call on the CDS is then given by:

$$
C S O_{\text {payoff }}\left(T_{\exp }\right)=\left[e^{\left(-K \cdot\left(T-T_{\text {exp }}\right)\right)} \cdot F R N_{R F}\left(T_{\exp }, T\right)-F R N_{D}\left(T_{\exp }, T\right)\right]^{+}
$$

In this work the risk free and the intensity processes will be modelled using a HW and a BK process respectively. In the next section we describe the algorithms.

\section{4) Hull - White and Black - Karazinsky Models}

In order to price a credit derivative security one in general needs at least a two-factor model: one for the interest rate and the other for the intensity process. In what follows we first show how to build the risk free and the intensity process separately, then we show how the two are integrated in a three dimensional like tree.

In some cases the assumption of independence between interest rates and intensity makes it possible to de-couple the payoff of a derivative in a way that one would not need to build a tree 
for the interest rate process. This is not however the most general case. For this reason in what follows we show how to develop a model which involves both a tree for the interest rate and a tree for the intensity process.

The whole algorithm follows very closely the two factor process algorithm described in Hull and White [1994]. In the next section we give a brief description of the HW and BK models and how they are integrated in a two factor model for credit derivatives (see Schonbucher [1999] for more details).

\section{1) The Risk Free Interest Rate Tree}

In this article we will assume that the interest rate process will follow the HW model (basically an Ornstein Ullenbeck process [1999]). I.e. we assume:

$$
d r=\left(\theta_{r}(t)-a_{r} \cdot r\right) \cdot d t+\sigma_{r} \cdot d B
$$

where $r, a_{r}$ and $\sigma_{\mathrm{r}}$ are the (unobserved) instantaneous short rate, mean reversion and volatility respectively.

The algorithm builds the dynamic of the interest rate process in a recombining trinomial tree structure. For each time step of length $\Delta t$ the short rate will assume values of the form $r(t+\Delta t)=$ $r(t)+k \cdot \Delta r$, where $k$ might be negative or positive integer and $\Delta r$ is given by:

$$
\Delta r=\sigma_{r} \cdot \sqrt{3 \cdot \Delta t}
$$


The branching probabilities at the nodes are evaluated by the use of three constraints: the first two moments of the process and the fact that probabilities add up to 1. One more constraint on the whole tree might be added: it may not grow indefinitely otherwise probabilities might become negative.

The steps in the building of the tree are then the following:

a) suppose in eq. 8 that $\theta_{\mathrm{r}}(\mathrm{t})$ is zero and build a symmetric tree for the $r$ process;

b) evaluate the value of $\theta_{r}(t)$ to be added at each node such that one might price correctly zero coupon bonds;

c) evaluate the values of $a_{r}$ and $\sigma_{\mathrm{r}}$ which would price correctly swaptions or caps/floors or any derivative which might be linked with the securities one needs to price.

The third step above is called calibration. Observe that by construction any values of mean reversion and volatility will lead to the correct prices of zero coupon bonds. The determination of the mean reversion and volatility to be used in each case is done by searching the values of the two parameters which give good prices of market available interest rate options.

In principle one could also use the HW model above proposed to model the evolution of the hazard rate (the default intensity). Indeed this was the approach proposed by Schonbucher [1999]. The HW model however does not preclude the values in the tree nodes to become negative ${ }^{4}$. As default intensities are related to default probabilities (see eq.1) negative intensities would lead to negative default probabilities.

In the next section we (briefly) describe the BK tree model.

\section{2) The Default Intensity Tree}

The default intensity process will obey the following stochastic differential equation: 


$$
d \ln (\lambda)=\left(\theta_{\lambda}(t)-a_{\lambda} \cdot \ln (\lambda)\right) \cdot d t+\sigma_{\lambda} \cdot d B
$$

where as before $a_{\lambda}$ and $\sigma_{\lambda}$ are the mean reversion and volatility for the intensity process, $\lambda$ is the intensity and $\ln$ is the natural logarithm.

The steps in building the tree are basically the same as described above and we refer to Hull and White [1994] for details. There are however two important points worth mentioning.

The first is that (see item $b$ ) of 4.1 above) in order to evaluate $\theta_{\lambda}(\mathrm{t})$ one needs the cumulative probability of non-default ${ }^{5}$ curve. In our case we implied this cumulative probability from the CDS spreads observed at the CDS market. The algorithm used is based on the work of Martin et alli [2001] and we refer to Garcia et alli [2001] for its use in present valuing CDS's.

The second and not less important aspect is how to calibrate the model. One should remember that by construction any value of $a_{\lambda}$ and $\sigma_{\lambda}$ will reproduce the cumulative probability given. I.e. by construction one prices exactly the defaultable bond associated with the cumulative default probability given as input. But in order to price options one still needs the option market to determine the values of the mean reversion and volatility (calibration). In here however there is no liquid option market for credit products. The approach we have used for the calibration is the following: we got from the market a price for an at the money (ATM) and an out of the money (OTM) CSO. The model was calibrated for the ATM and the parameters so determined have been used to price an OTM option. Later on we give a comment about this approach and we discuss an alternative methodology for the calibration.

In the next section we show how the two trees are integrated.

\section{3) The Credit Tree (HW + BK)}


The new integrated tree (called 3D tree in what follows) has the same number of time steps as the other two trees (called 2D trees). One should make sure that both 2D trees have the same time step interval. At each node in the new tree one may go to 9 possible nodes if there is no default or to one node in case of default (10 possible nodes in total).

A node in the $3 \mathrm{D}$ tree will be represented by $\mathrm{n}_{3 \mathrm{D}}(\mathrm{x}, \mathrm{y}, \mathrm{z})$, where the first index represents time step and the other two indexes are such that the interest rate comes from the node $\mathrm{n}_{\mathrm{RF}}(\mathrm{x}, \mathrm{y})$ in the interest rate tree, and the default intensity from the node $n_{D}(x, z)$ in the intensity tree.

The branching probabilities in the $3 \mathrm{D}$ tree are given in table 1 and the default probability in node $\mathrm{n}_{\mathrm{D}}(\mathrm{x}, \mathrm{y}, \mathrm{z})$ is given by:

$$
P_{\text {default }}(x, y, z)=1-e^{-n_{D}(x, z) \cdot \Delta t}
$$

INSERT Table 1 in here

From table 1 it is clear we are assuming independence between the two process (see section 5 for a comment about it).

\section{4) Using the Tree to price a CSO}

In this section we go in more detail on how to price a CSO on a CDS. Consider one wants to evaluate a one-year call CSO with strike K on a six year CDS. As we have already mentioned we will approximate it by pricing a put option on a defaultable FRN. For simplicity consider that the 
notional of the contract is $\mathrm{N}$, the recovery rate supposed fixed is $\alpha$. In what follows we will call the interest rate and the default intensity trees as $2 \mathrm{D}$ trees.

The steps to be followed are the following:

a) build a tree for the six year risk free FRN. Consider that $n_{R F}(x, y, z)$ and $n_{R F}(x, y)$ represents the node of the $3 \mathrm{D}$ and the $2 \mathrm{D}$ risk free FRN trees. Then we have:

$$
F R N_{R F}(x, y, z)=F R N_{R F}(x, y)
$$

in this way the value of the risk free FRN depends only on the values it has in the 2D tree nodes;

b) build a tree for the defaultable FRN (represented as FRN $\mathrm{D}_{\mathrm{D}}$ ). Consider that $\mathrm{T}_{\mathrm{FRN}}$ is the maturity of the $\mathrm{FRN}_{\mathrm{D}}$ (in our case $\mathrm{T}_{\mathrm{FRN}}=6$ ). At time $\mathrm{T}_{\mathrm{FRN}}$ we have:

$$
F R N_{D}\left(x_{T_{F R N}}, y, z\right)=N+C, \quad \forall y, z
$$

where $\mathrm{x}_{\mathrm{TFRN}}$ is the time step corresponding to time $\mathrm{T}_{\mathrm{FRN}}$ (the maturity date of the FRN). $\mathrm{C}$ is the coupon of the floater. The remaining nodes in the tree are calculated by backward induction as follows:

$$
\begin{array}{r}
F R N_{D}\left(x_{n}, y, z\right)=\left(e^{-\lambda\left(x_{n}, z\right) \cdot \Delta t}\right) \cdot\left(\sum_{i, j}\left[p\left(x_{n}, y_{i}, z_{j}\right) \cdot F R N_{D}\left(x_{n+1}, y_{i}, z_{j}\right) \cdot e^{-r\left(x_{n}, y\right) \cdot \Delta t}\right]+I\left(x_{n}\right) \cdot C\right) \\
+\left(1-e^{-\lambda\left(x_{n}, z\right) \cdot \Delta t} \cdot \alpha \cdot N\right)
\end{array}
$$


where $\lambda\left(x_{n}, z\right)$ and $r\left(x_{n}, y\right)$ are the values of the default intensity and risk free rate at nodes $\left(\mathrm{x}_{\mathrm{n}}, \mathrm{z}\right)$ and $\left(\mathrm{x}_{\mathrm{n}}, \mathrm{y}\right)$ in their respective trees. The $\mathrm{p}\left(\mathrm{x}_{\mathrm{n}}, \mathrm{y}_{\mathrm{i}}, \mathrm{z}_{\mathrm{j}}\right)$ is in fact a short cut notation to the following more cumbersome notation $\mathrm{p}\left(\left(\mathrm{x}_{\mathrm{n}}, \mathrm{y}, \mathrm{z}\right) \mid\left(\mathrm{x}_{\mathrm{n}+1}, \mathrm{y}_{\mathrm{i}}, \mathrm{z}_{\mathrm{j}}\right)\right)$ which means the probability in node $(y, z)$ at time $x_{n}$ of going to node $\left(y_{i}, z_{j}\right)$ at time $x_{n+1} . I\left(x_{n}\right)$ is the indicator function which is 1 if there is a coupon payment at time $x_{n}$ and 0 otherwise. The first factor in the eq. 15 is the value of the bond in case there is no default while the second factor gives the value in case of default.

c) build a tree for the CSO. Consider that $\mathrm{T}_{\mathrm{CSO}}\left(\mathrm{T}_{\mathrm{CSO}}<\mathrm{T}_{\mathrm{B}}\right)$ the expiry time of the option and that this corresponds to node $\mathrm{x}_{\mathrm{CSO}}$ in the $3 \mathrm{D}$ tree. Assuming that the strike in the option is $\mathrm{K}$ at the expiry of the (put) option we have that:

$$
C S O\left(x_{T c s o}, y, z\right)=\left[e^{-K \cdot\left(T_{B}-T_{c s o}\right)} \cdot F R N_{R F}\left(x_{T c s o}, y, z\right)-F R N_{D}\left(x_{T c s o}, y, z\right)\right]^{+}
$$

where as before the + sign means the maximum between 0 and the value between brackets. Assuming that in case of default of the FRN $\mathrm{N}_{\mathrm{D}}$ the option holder gets the recovery rate on the FRN then the remaining nodes in the tree are calculated as:

$$
\begin{aligned}
\operatorname{CSO}^{\text {eur }}\left(x_{n}, y, z\right)=\left(e^{-\lambda\left(x_{n}, z\right) \cdot \Delta t}\right) \cdot \sum_{i, j}\left[p\left(x_{n}, y_{i}, z_{j}\right) \cdot \operatorname{CSO}\left(x_{n+1}, y_{i}, z_{j}\right) \cdot e^{-r\left(x_{n}, y\right) \cdot \Delta t}\right] & \\
& +\left(1-e^{-\lambda\left(x_{n}, z\right) \cdot \Delta t} \cdot \alpha \cdot N\right)
\end{aligned}
$$

for the case of an European option. If the option is American (or Bermudan) we have:

$$
\begin{aligned}
\operatorname{CSO}^{a m}\left(x_{n}, y, z\right)= & \left(e^{-\lambda\left(x_{n}, z\right) \cdot \Delta t}\right) \cdot \max \left(\sum\left\lfloor p\left(x_{n}, y_{i}, z_{j}\right) \cdot \operatorname{CSO}\left(x_{n+1}, y_{i}, z_{j}\right) \cdot e^{-r\left(x_{n}, y\right) \cdot \Delta t}\right\rfloor\right. \\
& \left.e^{-K \cdot\left(T_{B}-T_{c s o}\right)} \cdot F R N_{R F}\left(x_{c s o}, y, z\right)-F R N_{D}\left(x_{c s o}, y, z\right)\right)+\left(1-e^{-\lambda\left(x_{n}, z\right) \cdot \Delta t} \cdot \alpha \cdot N\right)
\end{aligned}
$$


In the above formulation one simplifying assumption has been made: the option premium is paid up front. We also decided to count the defaultable coupon as being the risk free forward rate plus the spread.

A simplifying assumption is that the risk free forward rate will be evaluated using the current yield curve (it avoids the option to become path dependent). In this way the coupon of the $F R N_{D}$ is given by:

$$
C\left(t_{n}\right)=\left(f\left(0, t_{n-\&}, t_{n}\right)+K\right) \cdot\left(t_{n}-t_{n-1}\right)
$$

where $t_{n-1}$ and $t_{n}$ are the dates when the coupon rate is determined and paid respectively; $f\left(0, t_{n-1}, t_{n}\right)$ is the forward rate observed at time zero for the period between $t_{n-1}$ and $t_{n}$, and $K$ is the CDS strike rate in the option.

Moreover we will be pricing a Bermudan CSO and allow the exercise dates to be taken on payment dates only. The reason for it is that the value of the floater immediately after the coupon payment is face value. Otherwise to be absolutely precise one would need to determine the value of the coupon of the floater making the option to be path dependent. .

In the next section we give results of the pricing of Bermudan call CSO on a CDS with the model being calibrated to market prices (observe that a call on a CDS rate is a put on the defaultable FRN).

\section{5) Results}


In this section we show the results of pricing a Bermudan call CSO on a CDS. As already mentioned we have calibrated the HW interest rate tree for swaptions and then calibrated the intensity (BK) tree to an ATM American CSO and both prices have been taken from a market participant.

The mean reversion and volatility for the interest rate tree are respectively 0.012 and 0.009 . The risk free discount curve of the day is shown in table 2.

Table 2 In here

In order to build the BK intensity tree one will need to imply default probabilities. In table 3 we show the CDS credit spreads. The implied default probabilities are shown in table 4 .

Table3 in here

Table 4 in here

The prices for the ATM and the OTM CSO got from the market and from the tree are shown in table 5 . Both market prices are the bid prices ${ }^{7}$ by a large financial institution.

Table 5 in here

As it can be seen from table 5 the bid price from the model for the OTM CSO is higher than the one given by the market. Should one then conclude that the model is inadequate? Is there any utility in the model? How to interpret the results? 
There are several reasons for the discrepancies in the prices between the model and the market.

A first reason is that the credit derivatives market is still largely an OTC market. Even for the most liquid instrument (CDS's) bid offer spreads are very large (more than 10\%) and for the same referrence it can vary considerably from bank to bank. In our example the bid offer spread for the CDS was 30bp. The CDS curve used to imply the probabilities of default (table 3) was taken from the web site (a paid service) of a CDS market maker. Strictly speaking only the 3 and 5 year CDS quotes are considered to be liquid.

The CSO quote was taken from a second market maker as the one who provided access to its CDS curve did not want to commit to CSO quotes. We did not have access to the bid-offer spread on the CSO's quoted. Additionally the CSO quotes took one week to be given.

A second reason for the discrepancy in prices is that the model might systematically overprice OTM CSO calls. Indeed if the market would be using a BS like approximation (see Schonbucher [2000] for a BS formula price for European CSO's) we would have calibrated the model for a higher volatility (the ATM option) than then one used in pricing the OTM option (assuming smiles effects). Moreover as we assumed independence between interest rates and the intensity process, the current option might be more affected by the intensity process than by the interest rate process (see equation 4 for a hint on this point). As the BK process presents fatter tail distributions than the one expected by the BS process one again would expect higher prices for the OTM call.

A third reason would be the effect of an error on the assumed recovery rate when implying default probabilities from the CDS quotes. A fourth source of error is the independency assumption between interest and intensity rates. Concerning the independence assumption (as already reported in Schonbucher [1999]) we believe the model to be a lot more sensible to uncertainties in the recovery rate. For academic completeness we add that we are aware of a study 
from JP Morgan supporting the hypothesis that there is correlation between interest rates and default intensities.

Given the limitations above we think that the model did not score that bad. More research is necessary to check if indeed the overpricing of OTM call options is systematic (and for how much) as we believe. If this is the case the practitioner can use this model to mark to market the CSO positions.

Concerning the calibration process we note that we have used one option only. As we had only one ATM CSO available. This is linked to the difficulty in getting market quotes.

Alternatively instead of getting market quotes (to be used for calibration) one could use the Black Scholes formula (see Schonbucher [2000]) for european CSO's and calibrate the model to it. It happens that the BS model depends on default intensity volatilities and those volatilities are not yet available in the market. In an internal study (not yet available for publication) we have implied default probabilities from historical CDS curves and from them we evaluated historical intensity default volatilities. The volatilities are then used in the European CSO formula and compared with market quotes. Again we observed differences of the order observed in this work.

One last remark is the following: most of the questions above might only be answered when the credit derivatives market becomes more mature and data becomes available. In the present situation practitioners will have to continue coping with models that are only half understood in order to mark to market CSO exposures.

\section{6) Comments}

In this paper we have developed a two factor tree model to price Bermudan call CSO's on a CDS. Some approximations are done in considering the CSO as options on the spread between a defaultable and a risk free FRN. Although we have assumed independence between interest and 
default intensity rates, for completeness we have shown how to model the two processes and put them together. The model uses a HW tree for the interest rate dynamics and a BK tree for the intensity process.

The HW tree has been calibrated to swaption prices.

In the construction of the BK tree we have used a default probability curve that was implied from observed market CDS rates at the time of pricing. Once the BK tree is constructed it is then calibrated to an (ATM Bermudan) call CSO market quote. The parameters so determined are then used to price an (OTM Bermudan) call CSO.

Although we have observed that the model overprices the bid price of the OTM option we can not say that the price is out of the bid offer spread. The CSO market is still very illiquid and prices might vary considerably from bank to bank. Several problems will be met when trying to model a CSO of which we will mention four: a) lack of reliable intensity volatilities or even CDS rates; b) uncertainties about recovery rates; c) lack of CSO quotes for which to calibrate the model; d) uncertainties about correlation parameters between interest and intensity rate processes.

The way these uncertainties affects the price of a CSO will continue an area for future research.

As a final remark this paper shows the difficulties faced by practitioners who have to mark to market portfolios of CSO's. Most of them might be pricing via the hedge instruments and running the problems of imperfect hedges.

\section{Acknowledgements}

João Garcia would like to express his deeply gratitude to Eric Hermann (Head of Global Risk Management) of Dexia Holding and Peter Van Herwegen (Head of Accounting) of Dexia Bank for their patience, trust and incentives when in the implementation of all the necessary models 
used in this work. Without their view, support and management skills this sort of work would never have been possible. He would like to thank Dr. Philipp Schonbucher for spending a whole Sunday afternoon discussing the possibilities of calibrating the model here developed. Finally he also would like to thank Ronny Langendries and Tom Dewispelare from the Risk Methodology of Dexia Holding for their support and numerous discussions.

\section{End Notes}

${ }^{1}$ This analogy has been taken from Lando [1997]

2 The L could also have been made deterministically dependent on time. We refer to Duffie and Singleton [1994] for more details.

${ }^{3}$ In what follows expectations are taken with respect to the equivalent martingale measure (see Musiela and Rutkovisky [1997]). We have assumed that a lot of technical conditions are observed. We refer to Duffie and Singleton [1994] or Schonbucher [1999-2] for the deduction of the equation presented.

${ }^{4}$ The HW model is still used by some market participants despite the fact the it might give negative rate (they have indeed very low probabilities).

${ }^{5}$ The probability in question is given by $1-\mathrm{Q}(0, \mathrm{t})=\exp (-\lambda \mathrm{t})$ and it is the analogous of the discount factor curve used when building the risk free tree.

${ }^{6}$ As will be seen later on when pricing each probability in the table will still be multiplied by the probability of non-default.

${ }^{7}$ The CSO's are very exotic instruments traded only OTC. Market players are very reluctant to show information like bid offer spread unless they are very sure that the deal will be done. It took some time until a market player gave the quotes used in this study. 


\section{References}

Black F. and M Scholes “The Pricing of Options and Corporate Liabilities” Journal of Political Economy, 81 (1973), pp. 634-54.

Breemaud P Point Processes and Queues Martingale Dynamics. Springer-Verlag, 1981.

Das, S. “Credit Risk Derivatives" Journal of Derivatives 2 (3) (1995), pp. 7-23.

Duffie D. and K.J. Singleton "Modeling Term Structure of Defaultable Bonds" working paper

The Graduate School of Business, Stanford University, first version 1994.

Eom Y.H., J. Helwege, and J. Z. Huang, "Structural Models of Corporate Bond Pricing: An

Empirical Analysis" working paper of the Finance Department from Ohio State University, Columbus, OH 43210, USA, Oct. 2000.

Garcia J.B.C., G. Gielens, H. van Ginderen and R. Langendries "On the Pricing of Baskets Using Copulas” working paper Methodology Group, Dexia Bank, $3^{\text {rd }}$ Draft May 2002.

Garcia J., H. Van Ginderen, and R. Garcia, Present Valuing Credit Default Swaps: a Practitioner View, Bank en Financierwezen, Oct 2001.

Hull J. and A. White, Numerical Procedures for Implementing Term Structure Models II: Twofactor models, Journal of Derivatives, 2(2):37-48, 1994

Jarrow R., and S.M. Turnbull, Pricing Derivatives on Financial Securities Subject to Credit Risk, Journal of Finance, 50:53-85, 1995.

Jarrow R., D. Lando, and S.M. Turnbull, A Markov Model for the Term Structure of Credit Spreads. The Review of Financial Studies, 10(2):481-526, 1997.

Karatzas I.and S. Shreve, Brownian Motion and Stochastic Calculus, $2^{\text {nd }}$ Ed. Springer 1999. Lando D., On Cox Processes and Credit Risky Securities, Review of Derivatives Research, 2(2/3): 99-120, 1998. 
Lando D. "Modelling Bonds and Derivatives with Default Risk" Mathematics of Derivatives

Securities Edited by M.A.H. Dempster and S.R. Pliska, pag. 369-393, Cambridge University

Press 1997.

Longstaff, F. and E. Schwartz, A Simple Approach to Valuing Risky Fixed and Floating Rate

Debt, Journal of Finance, 50 (3) (1995), pp. 789-819.

Martin R., K. Thompson, C. Browne, Price and Probability, Risk Magazine, pag. 115-117, Jan 2001.

Merton, R.C., On the Pricing of Corporate Debit: The risk structure of interest rates, Journal of Finance, 29 (1974), pp. 449-470.

Musiela M. and M. Rutkovisky, Martingale Methods in Financial Modeling, Applications of Mathematics Stochastic Modelling and Applied Probability Vol. 36, Springer, Sept. 1997

Schonbucher P., Term Structure Modelling of Defaultable Bonds, The Review of Derivatives

Studies, Special Issue: Credit Risk, 2 (2/3):161-192, 1998.

Schonbucher P., A Tree Implementation of a Credit Spread Model for Credit Derivatives,

Working paper Department of Statistics University of Bonn, version June 1999.

Schonbucher P., Credit Risk Modelling and Credit Derivatives, Ph.D. Dissertation, Department of Statistics, Faculty of Economics, Bonn University, Fall 1999-2.

Schonbucher P., Libor Market Model With Defaul Risk, Working paper Department of Statistics University of Bonn, version December 2000. 


\section{Tables}

\begin{tabular}{|c|c|c|c|c|}
\hline & \multicolumn{4}{|c|}{ Default Intensity Move } \\
\hline & & Up & Middle & Down \\
\hline Interest & $\mathrm{Up}$ & $\mathrm{p}_{\mathrm{RF}}^{\text {up } * \mathrm{p}_{\mathrm{D}}^{\text {up }}}$ & $\mathrm{p}_{\mathrm{RF}}^{\text {up }} * \mathrm{p}_{\mathrm{D}}^{\text {middle }}$ & $\mathrm{p}_{\mathrm{RF}}^{\text {up } * \mathrm{p}_{\mathrm{D}}^{\text {down }}}$ \\
\hline Rate & Middle & $\mathrm{p}_{\mathrm{RF}}{ }^{\text {middle } * \mathrm{p}_{\mathrm{D}}{ }^{\text {up }}}$ & $\mathrm{P}_{\mathrm{RF}}^{\text {middle }} * \mathrm{p}_{\mathrm{D}}^{\text {middle }}$ & $\mathrm{p}_{\mathrm{RF}}$ middle $* \mathrm{p}_{\mathrm{D}}^{\text {down }}$ \\
\hline Move & Down & $\mathrm{p}_{\mathrm{RF}}{ }^{\text {down }} * \mathrm{p}_{\mathrm{D}}^{\text {up }}$ & $\mathrm{P}_{\mathrm{RF}}^{\text {down }} * \mathrm{p}_{\mathrm{D}}^{\text {middle }}$ & $\mathrm{p}_{\mathrm{RF}}{ }^{\text {down }} * \mathrm{p}_{\mathrm{D}}{ }^{\text {down }}$ \\
\hline
\end{tabular}

Table 1 Branching probabilities in the $3 \mathrm{D}_{\text {tree }}{ }^{6}$ 


\begin{tabular}{|c|c|}
\hline Date & Discount Factor \\
\hline $16 / 8 / 2001$ & 1.0000 \\
\hline $17 / 08 / 2001$ & 0.9998747 \\
\hline $20 / 08 / 2001$ & 0.9994978 \\
\hline $27 / 08 / 2001$ & 0.9986182 \\
\hline $3 / 09 / 2001$ & 0.9977382 \\
\hline $20 / 09 / 2001$ & 0.9956654 \\
\hline $22 / 10 / 2001$ & 0.9919294 \\
\hline $22 / 11 / 2001$ & 0.9886339 \\
\hline $20 / 2 / 2002$ & 0.9785173 \\
\hline $20 / 05 / 2002$ & 0.9695015 \\
\hline $20 / 8 / 2002$ & 0.9600748 \\
\hline $20 / 08 / 2003$ & 0.9205583 \\
\hline $20 / 08 / 2004$ & 0.8793688 \\
\hline $22 / 08 / 2005$ & 0.8371468 \\
\hline $21 / 08 / 2006$ & 0.7947228 \\
\hline $20 / 08 / 2007$ & 0.7521805 \\
\hline $20 / 08 / 2008$ & 0.7102778 \\
\hline $20 / 08 / 2009$ & 0.6695355 \\
\hline
\end{tabular}

Table 2 Risk Free Discount Factors Used in the Evaluations 


\begin{tabular}{|c|c|c|c|c|c|c|c|c|c|c|}
\hline Time (yr) & 1 & 2 & 3 & 4 & 5 & 6 & 7 & 8 & 9 & 10 \\
\hline Spread (bp) & 175 & 241 & 264 & 276 & 285 & 293 & 300 & 302 & 304 & 306 \\
\hline
\end{tabular}

Table 3 CDS Rates Used in the Determination of the Default Probability Curve 


\begin{tabular}{|c|c|}
\hline Date & Default Probability \\
\hline $16 / 08 / 2001$ & 0 \\
\hline $16 / 08 / 2002$ & 0.0342510 \\
\hline $16 / 08 / 2003$ & 0.0920711 \\
\hline $16 / 08 / 2004$ & 0.1474603 \\
\hline $16 / 08 / 2005$ & 0.1996514 \\
\hline $16 / 08 / 2006$ & 0.2505164 \\
\hline $16 / 08 / 2007$ & 0.3004684 \\
\hline $16 / 08 / 2008$ & 0.3487388 \\
\hline
\end{tabular}

Table 4 Cumulative Default Probability Curve 


\begin{tabular}{|c|c|c|}
\hline Strike (bp) & Market Price (bp) & HWBK Price (bp) \\
\hline 285 (ATM) & 160 & - \\
\hline 340 (OTM) & 105 & 135 \\
\hline \multicolumn{2}{|c|}{ ATM = at the money(used for calibration), OTM = out of the money } \\
\hline
\end{tabular}

Table 5 CSO prices used in evaluations 